\title{
An Evaluation of the Factors Influencing Participation in the National School Lunch Program (NSLP) for Latino Students During Middle School and High School Years
}

\author{
David Edens ${ }^{1}$, Adriana Lopez ${ }^{2}$, Lisa Kessler ${ }^{1}$, and Bonny Burns-Whitmore ${ }^{1}$ \\ ${ }^{1}$ Huntley College of Agriculture, California State Polytechnic University, Pomona \\ ${ }^{2}$ Rowland Unified School District
}

\begin{abstract}
Background and Purpose: In California, approximately 3.2 million students participated in the National School Lunch Program (NSLP in 2015). It is estimated that Latino students received over 760,000 meals through the NSLP program. This study evaluates factors that influence middle and high school Latino students' participation in the (NSLP). Methods: Study participants were a convenience sample of students $(n=232)$ utilizing a 22-question survey tool. The independent variables were grade level, gender, ethnicity, perceived social stigma, competitive foods served on and off campus, peer influences and parental influences. The dependent variable was participation in the NSLP. T-test, ANOVA, and Stepwise multiple regression were used to answer the research questions. Results: Latino students were not significantly different from non-Latino students in their participation rates in the NSLP. There were several significant predictors of NSLP participation for Latino students. Meal eligibility was the only significant predictor of participation in the NSLP for Latino students who are low-participators.

Conclusions: Latino students are different from non-Latino students in the factors that influence their participation in the NSLP. Future research is needed to clarify the factors impacting Latino NSLP participation.

(C) 2018 Californian Journal of Health Promotion. All rights reserved. Keywords: National School Lunch Program, Latino, School Meal Participation, School Meals
\end{abstract}

\section{Introduction}

The National School Lunch Program (NSLP) was established under the National School Lunch Act of 1946 with the primary goal of ensuring that schoolchildren do not go hungry and have access to nutritious meals and snacks that support normal growth and development (Fox \& Condon, 2012). It is a federally assisted meal program that operates in United States public and non-profit private schools and residential childcare institutions. In 2010, the Healthy Hunger-Free Kids act required that the U.S. Department of Agriculture update school meal nutrition standards in order to reflect the dietary recommendations outlined in the 2010 Dietary Guidelines for Americans (DGAs) (United States Department of Agriculture, 2012). The DGAs provide evidence-based food and beverage recommendations with the goal of promoting health, preventing chronic disease and helping people reach and maintain a healthy weight. Currently, meals served through the NSLP are designed to provide participating schoolchildren with a well-balanced, low-fat meal containing one-third of their daily nutrient requirements (Fox \& Condon, 2012). Evidence shows that meals served through the NSLP provide adequate nutrition and support student health (Fox \& Condon, 2012; Hanson \& Olson, 2013; Taber et al., 2013; Briefel et al., 2009) and participation has the potential to help decrease childhood obesity rates (Taber et al., 2013).

\section{NSLP Participation}

Literature suggests that Latino students are the most at risk for food insecurity and obesity (Ogen et al., 2014; Colement-Jensen et al., 2016; Fryar, 
Carroll, \& Ogden, 2012). According to recent figures, approximately 30.5 million school children participated in the NSLP nationwide in 2015, $72.6 \%$ of which received free or reduced price meals (United States Department of Agriculture: Food and Nutrition Service, 2016). In California, approximately 3.2 million students participated in the NSLP in 2015 (United States Department of Agriculture: Food and Nutrition Services, 2016). Latino students account for approximately $25 \%$ of all students enrolled in U.S. public schools and about one-third of the total students eligible for free or reduced meals through the NSLP (National Center for Education Statistics, 2016). Latinos represent the largest ethnic group in California at $38.6 \%$ of the total population, a number that is expected to continue to grow (United States Census Bureau, 2016) and Latino students make-up $53.97 \%$ of all public school students in California (California Department of Education, 2016). Latino students will continue to grow as a target population for the NSLP, especially in California, therefore it is crucial to elucidate the factors influencing their participation in the NSLP and potentially help increase their participation rates. Latino/Hispanic participation in the NSLP is estimated to be approximately $24 \%$ of the program nationally (Ralston, Newman, Clauson, Guthrie, \& Buzby, 2008). Additionally, California distributed over 3.2 million meals in AY 17-18 (California Department of Education, 2018). Using the national percentage, it could be extrapolated that Latinos received almost three-quarter of a million meals in AY 17-18.

Participation rates in the NSLP have been dropping in recent years from 31.8 million in 2011 to 30.5 million in 2015 (United States Department of Agriculture: Food and Nutrition Service, 2016). Additionally, NSLP participation rates are considerably lower for students at higher grade levels: $67 \%$ for elementary students compared to $62 \%$ for middle school students and $50 \%$ for high school students (School Nutrition Association, 2016). Decreased NSLP participation during middle school and high school years is concerning since these are years of marked growth and increased dietary needs (California Department of Public Health, 2013).
Previous research has demonstrated the significant effect of school lunch price, access to competitive foods, perceived social stigma, peer influences and parental/home influence on NSLP participation in the general population of school children (Akin et al., 1993; Bhatia, Jones, \& Reicker, 2011; Gleason 1995; Long, Henderson, \& Schwartz, 2010; Maurer 1984; Miller 2011; Snelling, Korba, \& Burkey, 2007; OhriVachaspati, 2014; Mirtcheva and Powell, 2009). There are no published studies that examine the factors influencing participation in the NSLP, specifically for Latino students, during middle and high school years.

Existing literature reveals only a few published studies where students provided direct input regarding their experience in the NSLP (Meyer \& Conklin, 1998; Meyer, 2000; Asperin et al., 2009; Castillo \& Lofton, 2012). Although these studies provide valuable insight into the factors that may influence student participation in the NSLP, the survey tools utilized failed to include questions related to other factors that may influence school lunch participation such as parental influences, peer pressure and competitive foods.

The purpose of this current study was to examine barriers to participation in the NSLP for Latino schoolchildren at middle school and high school grade levels and to discover what factors influence their decision to consume school meals.

\section{Methods}

\section{Participants}

After approval by the university's Institutional Review Board, a survey was conducted to gather the data. This study utilized participants $(n=232)$ in $7^{\text {th }}$ through $12^{\text {th }}$ grade from four school sites located in Southern California, within ABC Unified School District: two high schools (AHS and GHS) and two middle schools (RMS and FMS). The largest number of participants were recruited from GHS ( $n=94)$ and the majority of the study participants were female $(n=135)$ The overall characteristics of the sample population are presented in Table 1.

The sample participants were primarily Hispanic/Latino (52\%) and a majority were eligible for either free or reduced fee lunches 
(68\%). Half of the those surveyed used the school lunch program between one and four daysper-week. Participants were well distributed across all six grade levels with the slightly more students in $10^{\text {th }}$ grade $(n=53)$. More than half of the survey respondents were of Latino ethnicity (52\%).

\section{Survey Instrument}

Study participants completed a survey consisting of seven characteristics questions and 15 questions relating to the proposed factors influencing NSLP participation. Demographic data was collected including gender, grade level, and ethnicity. Additionally, the survey included a question that identified NSLP eligibility. The dependent variable for the study was "How often do you eat a school lunch?” (Never, 1-2 days per week, 3 days per week, 4 days per week, and 5 days per week).

Fifteen questions related to factors that may affect student participation in the NSLP: personal food preferences/perceived quality of school lunches, perceived healthfulness of school lunches, competitive foods, social stigma/peer pressure and home environment/parental influences. These independent variables were scored on a Likert-type scale $(0=$ Strongly disagree to $7=$ Strongly agree). The questions are listed in each of the blocks in Table 2. The modified survey instrument was adapted from the validated Participation \& Non-Participation Surveys published by the National Food Service Management Institute (NFSMI) (Asperin et al., 2009; Rushing, 2013).

\section{Statistical Analyses}

Data collected were analyzed using Statistical Package for Social Sciences version 23 (International Business Machines Corporation, 2017). Missing cases were deleted using listwise deletion. A student $t$-test was used to determine if Latino students differ significantly from nonLatinos in their rates of school lunch participation. Multiple regression analysis was performed to determine the effectiveness of a model to predict school lunch participation for Latino and non-Latino students. The same regression model was used to determine the significant predictors of NSLP participation among all Latino students who participate in the NSLP versus those who participate at low rates (2 or less times per week.

\section{Results}

Descriptive analyses were performed to characterize the sample size, including information about school, gender, grade level, ethnicity, meal eligibility, NSLP participation, frequency of family meals/week and parent's highest level of education (Table 1, $n=231$ ). Missing points are noted with each characteristic. Additionally, we ran an independent samples ttest to determine whether Latinos and nonLatinos varied on their NSLP participation. There was no significant difference $(\mathrm{M}=1.97$, $\mathrm{SD}=1.50)$ and non-Latino $(\mathrm{M}=1.91, \mathrm{SD}=1.69)$ students; $t(229)=.29 ; p=0.08$. Five participants who did not know their ethnicity were pooled into the non-Latino group. 
Edens, D., Lopez, A., Kessler, L., Burns-Whitmore, B. / Californian Journal of Health Promotion 2018, Volume 16, Issue 2, Pages 1121.

Table 1.

Study Participant Characteristics

\begin{tabular}{|c|c|c|c|}
\hline Characteristic & & $n$ & $\%$ \\
\hline \multirow[t]{4}{*}{ School } & AHS & 60 & 26 \\
\hline & GHS & 94 & 41 \\
\hline & FMS & 23 & 10 \\
\hline & RMS & 55 & 24 \\
\hline \multirow[t]{2}{*}{ Gender } & Male & 94 & 41 \\
\hline & Female & 135 & 58 \\
\hline \multirow[t]{6}{*}{ Grade Level } & $7^{\text {th }}$ & 44 & 19 \\
\hline & $8^{\text {th }}$ & 34 & 15 \\
\hline & $9^{\text {th }}$ & 22 & 9 \\
\hline & $10^{\text {th }}$ & 53 & 23 \\
\hline & $11^{\text {th }}$ & 42 & 18 \\
\hline & $12^{\text {th }}$ & 36 & 16 \\
\hline \multirow[t]{8}{*}{ Ethnicity } & White/ Caucasian & 14 & 6 \\
\hline & Hispanic/Latino & 121 & 52 \\
\hline & Black/African American & 18 & 8 \\
\hline & Asian/Asian Indian & 40 & 17 \\
\hline & Native American/American Indian & 1 & 0 \\
\hline & Other & 16 & 7 \\
\hline & Multi ethnic Latino & 11 & 5 \\
\hline & Multiethnic Non-Hispanic & 5 & 2 \\
\hline \multirow[t]{4}{*}{ Meal Eligibility } & Free & 125 & 54 \\
\hline & Reduced & 32 & 14 \\
\hline & Paid & 36 & 16 \\
\hline & Don't know & 39 & 17 \\
\hline \multirow{5}{*}{$\begin{array}{l}\text { School Lunch } \\
\text { Participation }\end{array}$} & Never & 53 & 23 \\
\hline & 1-2 Days per week & 63 & 27 \\
\hline & 3 Days per week & 25 & 11 \\
\hline & $4 \quad$ Days per week & 28 & 12 \\
\hline & $5 \quad$ Days per week & 62 & 27 \\
\hline \multirow{4}{*}{$\begin{array}{l}\text { Frequency of Meals } \\
\text { eaten as a family per } \\
\text { week }\end{array}$} & 0 & 8 & 3 \\
\hline & $1-2$ & 55 & 24 \\
\hline & $3-4$ & 57 & 25 \\
\hline & Everyday & 110 & 47 \\
\hline \multirow{7}{*}{$\begin{array}{l}\text { Highest Level of Parent } \\
\text { Education }\end{array}$} & No high school diploma & 29 & 13 \\
\hline & High School Diploma & 33 & 14 \\
\hline & Some College & 48 & 21 \\
\hline & Bachelor's degree & 40 & 17 \\
\hline & Master's Degree & 18 & 8 \\
\hline & Doctoral Degree (PhD) & 4 & 2 \\
\hline & Don’t know & 59 & 25 \\
\hline
\end{tabular}




\section{Regression Analyses}

Table 2 summarizes the results of the regression analysis for Latino and non-Latino study participants; eight participants were dropped from this analysis due to not providing an answer to one or more of the survey questions. For Latino students, the significant predictors of NSLP participation were parental level of education $(\beta=0.14)$, frequency of family meals $(\beta=0.17)$, and meal eligibility being the most significant predictor $(\beta=-0.40)$. Not surprisingly, meal eligibility strongly predicts a lower rate of NSLP participation among students who do not qualify for free or reduced school meals. Only one of the factors of perceived social stigma and bringing food from home was significant: "I do not eat school lunches because I am worried about being judged negatively by my classmates". The final model predicting NSLP participation for Latino students accounted for $35.3 \%\left(R^{2}{ }_{a d j}=0.381\right)$ of the variation in level of NSLP participation $(F(21$, 107) $=4.75, p<0.001)$.

For non-Latino students, there was only one significant predictor of NSLP participation: bringing lunch from home $(\beta=-0.32)$. This result suggests that a higher frequency of bringing lunch from home decreases rates of NSLP participation among non-Latino students. Dislike in taste of school lunch and parent concern that school meals are unhealthy were not significant, suggesting that a stronger dislike for the taste of school meals and higher parental concerns that school meals are unhealthy decreases rates of NSLP participation, but were not significant. Surprisingly, meal eligibility is not a significant predictor in NSLP participation among nonLatino students. Thus, unlike with Latino students, lower participation in the NSLP would not be predicted among non-Latino students who do not qualify for free or reduced school meals. The final model predicting NSLP participation for non-Latino students accounted for 22.8\% $\left(R^{2}{ }_{a d j}=0.228\right)$ of the variation in level of NSLP participation $(F(21,73)=2.32, p<0.01)$.

\section{Comparison of all Latino students with low} NSLP participating Latino students

A separate regression analysis was run to compare all Latino students with low NSLP participation utilizing the same model used to compare non-Latino students to Latino students. The results are presented in Table 3.

Low participators were defined as consuming school lunch two times per week or less. Results of this regression analysis revealed only one significant predictor of NSLP participation among Latino low-participators: Meal eligibility $(\beta=-0.40)$. Not surprisingly, meal eligibility predicts lower participation among students who do not qualify for free and/or reduced lunches. The final model predicting NSLP participation for Latino students who are low-participators accounted for $32.2 \% \quad\left(R_{a d j}^{2}=0.322\right)$ of the variation in level of NSLP participation $(F(21$, $41)=2.40, p<0.01)$.

\section{Brief Analysis of Open-ended Questions on Survey Tool}

Two open-ended questions of the survey tool were meant to gather information regarding any other factors that may be affecting NSLP participation. One asked students to list the reasons they do not eat school lunches and the other asked for students to write down any other comments/concerns they wanted to share regarding school lunches. Although not formally analyzed in this study, a visual inspection of the qualitative data collected through these questions revealed the following reoccurring topics:

- Time constraints/busy student schedules

- Limited availability of desired menu items

- Not wanting to wait in line. 
Edens, D., Lopez, A., Kessler, L., Burns-Whitmore, B. / Californian Journal of Health Promotion 2018, Volume 16, Issue 2, Pages 1121.

Table 2.

Results of Stepwise Regression Analysis of Variables on NSLP Participation for Latino \& non-Latino Students

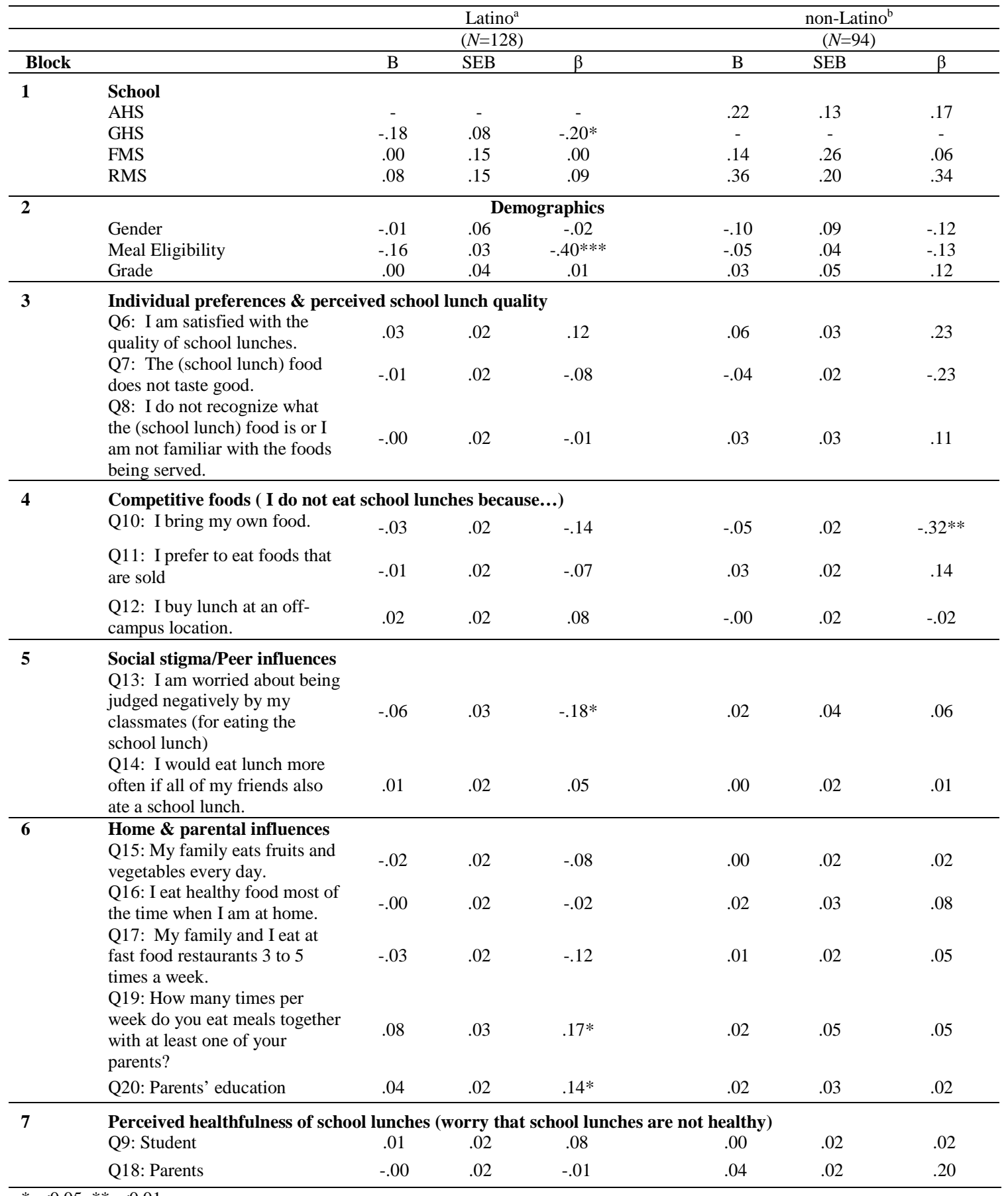

${ }^{*} p<0.05, * * p<0.01$

${ }^{\text {a }} F(21,107)=4.75, p<.001 ; R_{a d j}^{2}=.381$

${ }^{b} \mathrm{~F}(21,73)=2.32, p<.01 ; R^{2} a d j=.228$ 
Table 3.

Results of Regression Analysis of Variables on NSLP Participation for Latinos

\begin{tabular}{|c|c|c|c|c|c|c|c|}
\hline & & \multicolumn{3}{|c|}{$\begin{array}{l}\text { All Latino Participators }{ }^{\mathrm{a}} \\
\qquad(N=128)\end{array}$} & \multicolumn{3}{|c|}{$\begin{array}{l}\text { Latino Low Participators }^{\text {b }} \\
\qquad(N=62)\end{array}$} \\
\hline & & B & SEB & $\beta$ & B & SEB & $\beta$ \\
\hline \multirow[t]{5}{*}{ Block 1} & School & & & & & & \\
\hline & AHS & - & - & - & .19 & .17 & .17 \\
\hline & GHS & -.18 & .08 & $-.20 *$ & - & - & - \\
\hline & FMS & .00 & .15 & .00 & .02 & .27 & .01 \\
\hline & RMS & .08 & .15 & .09 & .20 & .33 & .18 \\
\hline \multirow[t]{4}{*}{ Block 2} & Demographics & & & & & & \\
\hline & Gender & -.01 & .06 & -.02 & .05 & .13 & .05 \\
\hline & Meal Eligibility & -.16 & .03 & $-.40 * * *$ & -.17 & .06 & $-.40 * *$ \\
\hline & Grade & .00 & .04 & .01 & -.07 & .09 & -.25 \\
\hline \multirow[t]{4}{*}{ Block 3} & Individual preferences \& perc & d schoo & ench & ality & & & \\
\hline & Q6 & .03 & .02 & .12 & -.01 & .04 & -.03 \\
\hline & Q7 & -.01 & .02 & -.08 & -.03 & .03 & -.14 \\
\hline & Q8 & -.00 & .02 & -.01 & -.02 & .04 & -.07 \\
\hline \multirow[t]{4}{*}{ Block 4} & Competitive foods & & & & & & \\
\hline & Q10 & -.03 & .02 & -.14 & -.04 & .03 & -.20 \\
\hline & Q11 & -.14 & .02 & -.07 & -.02 & .03 & -.10 \\
\hline & Q12 & .02 & .02 & .08 & .02 & .04 & .08 \\
\hline \multirow[t]{3}{*}{ Block 5} & Social stigma/Peer influences & & & & & & \\
\hline & Q13 & -.06 & .03 & $-.18 *$ & -.10 & .06 & -.30 \\
\hline & Q14 & .01 & .02 & .05 & .03 & .04 & .11 \\
\hline \multirow[t]{6}{*}{ Block 6} & Home \& parental influences & & & & & & \\
\hline & Q15 & -.02 & .02 & -.08 & -.04 & .04 & -.16 \\
\hline & Q16 & -.00 & .02 & -.02 & -.01 & .05 & -.02 \\
\hline & Q17 & -.03 & .02 & -.12 & -.04 & .04 & -.13 \\
\hline & Q19 & .08 & .03 & $.17 *$ & .06 & .06 & .12 \\
\hline & Q20 & .04 & .02 & .14 & .06 & .05 & .17 \\
\hline \multirow[t]{3}{*}{ Block 7} & Perceived healthfulness of sch & unches & & & & & \\
\hline & Q9 & .01 & .02 & .08 & .05 & .03 & .21 \\
\hline & Q18 & -.00 & .02 & -.01 & -.02 & .03 & -.10 \\
\hline
\end{tabular}

${ }^{*} p<0.05, * * p<0.01, * * * p<0.001$

${ }^{a} F(21,107)=4.75, p<.001 ; R^{2}{ }_{a d j}=.381$

${ }^{\mathrm{b}} F(21,41)=2.40, p<.01 ; R^{2}{ }_{a d j}=.322$

\section{Discussion}

Prior to this study, previous studies have not examined factors influencing participation in the NSLP for Latino students during middle and high school years. Additionally, no study had utilized a comprehensive survey tool including a wide range of factors that may be influencing participation in the NSLP. This study provided a better understanding of the factors that may be influencing the participation in the NSLP for Latino and non-Latino students.

The primary findings of this study were: (1) Latino students do not differ significantly from non-Latino students in their participation in the NSLP (2) The significant predictors of NSLP participation for Latino students are meal eligibility, parental level of education, Frequency 
of family meals and frequency of fast food consumption (3) The factors predicting participation in the NSLP are different for Latino and non-Latino students and (4) The factors predicting participation in the NSLP are different for Latino high-participators and Latino lowparticipators. (5) For non-Latino students, bringing lunch from home was the only significant predictor of NSLP participation. These results illustrate the need for further studies focused on the factors influencing NSLP participation specifically for Latino students.

The regression analysis performed on high versus low NSLP participants revealed that there were no significant predictors of participation for Latino high participators and only one significant predictor of participation for Latino low participators: Meal Eligibility. These findings indicate that more research is necessary to create a model that includes more significant predictors of NSLP participation for Latino students who are low and high participators. Furthermore, these results suggest that the model predicting NSLP participation for Latinos who are low participators may include completely different factors than the model predicting NSLP participation for Latino students who are high participators.

Other studies have found a significant relationship between NSLP participation and school lunch price, access to competitive foods, perceived social stigma, peer influences and parental/home in the general population of schoolchildren (Akin et al., 1993; Bhatia, Jones, Reicker, 2001; Gleason, 1995; Long, Henderson, Schwartz, 2010; Maurer, 1984; Miller, 2011; Snelling, Korba, Burkey, 2007; Mirtchea and Powell, 2009). In this study, we were able to demonstrate the significant effect of meal eligibility, parental level of education, frequency of family meals, and frequency of fast food consumption on NSLP participation for Latino students. Compared to previous studies, the current study utilized a more comprehensive survey tool but had a much smaller sample size. Although included in the survey tool, competitive foods, peer pressure/perceived social stigma were not found to be significant predictors of NSLP participation in either non-Latino or Latino students. These results contradict results from previous studies in the factors affecting NSLP participation. This discrepancy may be due to a difference in the validity of the survey tool used in our study compared to the survey tools used in previous research.

\section{Study Limitations}

This study was not without limitations. The study population was limited to students within ABC Unified School District (Southern California) and may not be representative of the student population within all school districts across the United States. Additionally, data collected is based on student self-report and may not be as accurate as data collected by other means. For instance, it may have been more reliable to collect information regarding NSLP eligibility and participation rates for each student by utilizing the schools point of sale computer database. It is possible that our study population is inherently biased due to the fact that only the students who were allowed to participate in this study were those whose parents took the time to sign and return a consent form. This may have resulted in an inadvertent selection bias towards students whose parents are more actively involved in their child's education.

Another limitation to this study was that the survey tool utilized was not pilot tested and validated. Because of this, it is possible that the terms used in the study survey tool may have been interpreted differently by each student, leading to skewed results. A pilot test could have benefited our analysis in that it would have identified any terms that needed further clarification. Additionally, validation of the current survey tool would confirm that the each of the survey questions actually measured the factors they were intended to measure.

A very significant limitation to our study is that our findings are based on regression analysis. In regression analysis, the beta weights analyzed only hold true for the particular combination of variables included in the predictive equation. Thus, it is impossible to discern the predictive power a single variable would have on its own. Additionally, regression analysis does not prove causality. Future research could focus on fine- 
tuning the predictive equation used by removing the factors that were shown not to be significant predictors in our study.

Lastly, our survey failed to include questions on lunch price, customer service and time constraints -- factors that have been shown to impact student NSLP participation (Meyer and Conklin, 1998; Meyer, 2000; Asperin et al., 2009; Castillo and Lofton, 2012). Future studies could improve the survey tool used in our study by adding questions related to these missing factors.

A confounding variable in our study may have been income. The survey tool did not inquire about family income, primarily because it was predicted that student-reported family income would be very inaccurate. One improvement to the current study could be to incorporate a phone survey with parents to determine family income.

\section{Implications for Future Research}

Based on the findings in this study, it is evident that Latino students are different from non-Latino students in the factors that influence their participation in the NSLP. Future research is needed in order to discover all of the factors that influence NSLP participation for Latino students. A follow-up study to this investigation could lead to the development of a more comprehensive validated survey tool for NSLP participation. A larger sample size could also improve the statistical power of study findings. It may also prove useful to compare the data collected from NSLP participant and non-participant groups within each ethnicity. Our regression equation could also be tested against a new sample of students to see how well it predicts NSLP participation.

Future research could include more of a mixedmethods approach involving the analysis of qualitative and quantitative data. Qualitative data could help elucidate what factors account for variance in NSLP participation unaccounted for through our investigation.

\section{Conclusion}

Participation in the NSLP offers many potential benefits to students. The current study evaluated the factors influencing NSLP participation for Latino students during Middle and High School years. The results of this study show that meal eligibility, parental level of education, frequency of family meals, and frequency of fast food consumption are all significant predictors of NSLP participation for Latino students. Future research focusing on the Latino student population is needed in order to reveal all other undiscovered factors that influence Latino student participation in the NSLP. Despite its limitations, the current study provided valuable insight into the factors that influence participation in the NSLP for Latino students in particular and may serve to guide future research focused on Latino students in the NSLP.

\section{References}

Akin JSl, Guilkey DK, Popkin BM, Wyckoff JH. (1993) The demand for school lunches: an analysis of individual participation in the school lunch program. Journal of Human Resources, 17, 213-230.

Asperin AE, Nettles, M.F., Carr, D., \&, Hubbard S. (2009) High school students and school nutrition directors help develop surveys for increasing participation and satisfaction with the National School Lunch Program. The University of Mississippi: National Food Service Management Institute: Insight.

Bhatia R, Jones P, Reicker Z. (2011) Competitive foods, discrimination, and participation in the National School Lunch Program. American Journal of Public Health, 101, 1380-1386.

Briefel RR, Crepinsek MK, Cabili C, Wilson A, Gleason PM. (2009) School food environments and practices affect dietary behaviors of US public school children. Journal of the American Dietetic Association, 109, S91-107.

California Department of Education (CDE). Fingertip Facts on California - CalEdFacts, 2016. Retrieved February 9, 2016 from http://www.cde.ca.gov/ds/sd/cb/ceffingertipfacts.asp 
Edens, D., Lopez, A., Kessler, L., Burns-Whitmore, B. / Californian Journal of Health Promotion 2018, Volume 16, Issue 2, Pages 1121.

California Department of Education. (2018). Unduplicated student poverty - Free or reduced price meals data 2017-18. Retrieved from: https://www.cde.ca.gov/ds/sd/sd/filessp.asp

California Department of Public Health. (2013) Adolescent Nutrition. California Nutrition and Physical Activity Guidelines for Adolescents. Vol 39.

Castillo A, Lofton KL. (2012) Development of middle/junior high school student surveys to measure factors that impact participation in and satisfaction with the National School Lunch Program: University, MS: National Food Service Management Institute.

Coleman-Jensen A, Rabbitt MP, Gregory CA, Singh A. (2016) Household Food Security in the United States in 2015. United States Department of Agriculture, ERR-215.

Fox N, Condon E. (2012) School Nutrition Dietary Assessment Study-IV: Summary of Findings: United States Department of Agricultural: Food and Nutrition Services, Office of Research and Analysis.

Fryar C, Carroll M, Ogden C. (2012) Prevalence of obesity among chidren and adolescents: United States, trends 1963-1965 through 2009-2010. National Center for Health Statistics: Center for Disease Control and Preventation.

Gleason PM. Participation in the National School Lunch Program and the School Breakfast Program. (1995) American Journal of Clinical Nutrition, 61, 213S-220S.

Hanson KL, Olson CM. ( 2013) School meals participation and weekday dietary quality were associated after controlling for weekend eating among U.S. school children aged 6 to 17 years. Journal of Nutrition, 143, 714-721.

International Business Machines Corporation. (2017) IBM SPSS (Version 23.0). Armonk, NY

Long MW, Henderson KE, Schwartz MB. (2010) Evaluating the impact of a Connecticut program to reduce availability of unhealthy competitive food in schools. Journal of School Health, 80, 478486.

Maurer KM. (1984) The National Evaluation of School Nutrition Programs: factors affecting student participation. American Journal of Clinical Nutrition, 40, 425-447.

Meyer MK, Conklin MT. (1998) Variables affecting high school students' perceptions of school foodservice. Journal of the American Dietetic Association, 98, 1424-1431.

Meyer MK. (2000) Top predictors of middle/junior high school students' satisfaction with school foodservice and nutrition programs. Journal of the American Dietetic Association, 100, 100-103.

Miller DP. (2011) Associations between the home and school environments and child body mass index. Social Science \& Medicine, 72, 677-684.

Mirtcheva DM, Powell LM. (2009) Participation in the national school lunch program: importance of school-level and neighborhood contextual factors. Journal of School Health, 79, 485-494.

National Center for Education Statistics: Institute of Education Sciences. Racial/Ethnic enrollment in public schools. Retrieved January 9, 2016, from website, https://nces.ed.gov/programs/coe/indicator_cge.asp

Ohri-Vachaspati P. (2014) Parental perception of the nutritional quality of school meals and its association with students' school lunch participation. Appetite, 74, 44-47.

Ogden CL, Carroll MD, Kit BK, Flegal KM. (2014) Prevalence of childhood and adult obesity in the United States, 2011-2012. Journal of the Amernican Medical Association, 311, 806-814.

Ralston, K., Newman, C., Clauson, A., Guthrie, J., \& Buzby, J. (2008). The national school lunch program: Background, trends, and issues (61). Retrieved from https://files.eric.ed.gov/fulltext/ED502404.pdf

Rushing K. (2013) Administering school lunch participation and non-participation based surveys to middle school students. Journal of Child Nutrition \& Management, 37.

School Nutrition Association. (2016) School Operations Nutrition Report: The State of School Nutrition 2016. National Harbor, MD.

Snelling AM, Korba C, Burkey A. (2007) The national school lunch and competitive food offerings and purchasing behaviors of high school students. Journal of School Health, 77, 701-705. 
Taber DR, Chriqui JF, Powell L, Chaloupka FJ. (2013) Association between state laws governing school meal nutrition content and student weight status: implications for new USDA school meal standards. Journal of the American Medical Association Pediatrics, 167, 513-519.

United States Census Bureau. Quick-Facts: United States. Retrieved March 5, 2016 from http://www.census.gov/quickfacts/table/PST045215/00

United States Department of Agriculture: Food and Nutrition Service. (2016) Child Nutrition Tables: National School Lunch Program.

United States Department of Agriculture, Office of Communications USDA. Unveils Historic Improvements to Meals Served in America's Schools: New Standards Will Improve the Health and Well-being of 32 Million Kids Nationwide. (2012) News Release No. 0025.12.

Acknowledgements: The authors wish to acknowledge the Cal Poly Pomona undergraduate students who assisted with coding and tabulation of study data and Holly M. Greene, M.S. (Cal Poly Pomona) for providing manuscript editorial support.

\author{
Author Information \\ David Edens, PhD, MHA \\ Huntley College of Agriculture \\ California State Polytechnic University, \\ Pomona, CA 91768 \\ 909-869-2164, dredens@cpp.edu
}

